\title{
The Necessity of Integrating Family and Couple Therapy Services in Primary Healthcare Programs
}

\author{
Maryam Mohseny ${ }^{1 *}$, Tahereh Hamzeh Poor Haghighy ${ }^{2}$ \\ ${ }^{1}$ Department of Community Medicine, Shahid Beheshti University of Medical Sciences, Tehran, Iran \\ ${ }^{2}$ Department of Psycology, Lahijan Branch,Islamic Azad University, Lahijan, Iran
}

Corresponding Author: Maryam Mohseny, MD, Assistant Professor, Department of Community Medicine, Shahid Beheshti University of Medical Sciences, Tehran, Iran. Tel: 09124755933, Email: mohseny.maryam0@gmail.com

$\mathrm{T}$ The nuclear (core) or ideal family, which traditionally includes wife, husband, and children, is the most important and universal institution all over the world. It plays a crucial and decisive role in the mental health of the individual and of society. Families that are in trouble could be a source of tension for each individual in the family, and the unhealthy relationships between these individuals will also severely affect other people in the community. ${ }^{1}$ The main objectives of the current study were to examine the challenges ahead and to provide operational and effective strategies to overcome these challenges.

1. The importance of addressing the family system as one of the most important concerns of health systems can be easily explained by the increasing number of divorces and the decline in marriage rates. A survey on the status of marriage and divorce in Iran between the years 2011 and 2017 showed that during this period, marriage had a negative change of $30 \%$ and divorce had a positive change of $22.2 \%$. It is necessary to note that the current statistics are related to nuclear families. Today, however, except for nuclear or ideal families, new forms of families under the titles of cohabiting families, single parents, white marriages, etc. can also be seen. Because of their extreme difference from the ideal family, they can be considered as a major threat to the social system. It is important to mention that the problem of new forms of families is a global trend which is noticeable in other countries as well. ${ }^{2,3}$

2. The serious threat to the family system and the massive changes that have occurred in the community in recent years have attracted the attention of specialists in this area and have led to the formation of areas such as family therapy, couple therapy, marriage counseling, family counseling, and even the establishment of family protection laws. Despite the increasing number of problems that can be seen in the family system, there are few major macro-level policies in the Ministry of Health, the most important institution of healthcare. It is highly necessary to integrate family-based education and family therapy programs into macro-level policies in Iran.

\section{Family Therapy}

Family therapy is a type of group therapy in which the treatment unit is the family. In treatment sessions, one or more therapists deal with either all or a number of members of the family. The purpose of these sessions is to reduce or resolve unhealthy conflicts and anxiety within the family unit. Different types of family therapy include systemic family therapy, strategic, system-based, and solution-focused family therapy, structural family therapy, behavioral and cognitive-behavioral family therapy, experience-based family therapy, and family therapy based on psycho-analytical and combination-eclectic therapies. ${ }^{4,5}$

\section{Family Therapy Challenges in Iran}

1. Despite the importance and high effectiveness of this preventive and therapeutic method and given that the psychosocial counseling and treatment system in the public sector in Iran is very weak and is based mostly in the private sector, there is no comprehensive coverage. Most people who need such care are even unaware such service exists.

2. Family therapy requires therapists to be aware of a series of tutorials, protocols, and tools. Unfortunately, Iran is very weak in the field of codification or localization of guidelines.

\section{Couple Therapy}

Couple therapy is a kind of psychotherapy that aims to reduce marital inconsistencies and conflicts and create psychological

Copyright $\odot 2019$ The Author(s). This is an open-access article distributed under the terms of the Creative Commons Attribution License (http:// creativecommons.org/licenses/by/4.0), which permits unrestricted use, distribution, and reproduction in any medium, provided the original work is properly cited. 
balance in the interaction of two people. Conflict between spouses can have psychological, sexual, social, economic, ideological, and political origins and sources. ${ }^{6}$ Although each of these causes is important in its own place, the issue of sexual health is a topic that is very important in consolidating the family structure. The WHO has been active in the field of sexual health since 1974. In 2004, the WHO officially announced that many diseases and disorders in the world are due to ignorance of sexual health. ${ }^{7}$ Therefore, health systems cannot disregard sexual health.

\section{Couple Therapy Challenges in Iran}

1. Like family therapy, couple therapy has not worked strongly in the public sector except for pre-marital counseling.

2. In many societies, including Iran, sex issues are in the state of silence, denial, and negligence. Policymaking studies, as a tool for providing community-based information, are of particular importance for any decision-making, policy-making, and proper planning to meet the needs and constraints of sexual and reproductive health and improve the current status. At present, Iran has very few programs in this area; such therapy is being performed case by case.

\section{Main Suggestions}

- Provision of family and couple therapy services by skilled experts in the primary healthcare system

- Policy-making for the promotion and expansion of couple therapy, sexual health clinics, ${ }^{8}$ and communitybased interventions in this area.

\section{Authors' Contributions}

Both authors contributed equally to the study.

\section{Conflict of Interest Disclosures}

The authors declare that they have no conflicts of interest.

\section{References}

1. Alexander JF, Sexton TL. Functional family therapy. In: Murrihy RC, Kidman AD, Ollendick TH, eds. Clinical handbook of assessing and treating conduct problems in youth. New York: John Wiley; 2011.

2. Different-family-types. https://www.betterhelp.com/advice/family/ there-are-6-different-family-types-and-each-one-has-a-uniquefamily-dynamic.

3. Analysis of Marriage and Divorce Statistics in Iran. https://www. seratnews.com/fa/news/411273.

4. Josephson AM. From family therapy to family intervention. Child Adolesc Psychiatr Clin N Am. 2015;24(3):457-470. doi:10.1016/j. chc.2015.02.002

5. Bowen M. Family Treatment in Clinical Practice. New York: Jason Aronson; 1978.

6. Akbari M, Dinarvand FA. Effectiveness of therapy based on teaching choice theory on reduction of negative emotional reactions between couples with marital conflicts international. J Basic Sci Appl Res. 2014;3:38-41. [Persian].

7. World Health Organization (WHO). Developing sexual health programmes: a framework for action. WHO; 2013.

8. World Sexual Health Day 2016. http://www.worldsexology.org/ news/world-sexual-health-day/. 